\title{
MEGA-EVENTOS E ESPETÁCULOS RELIGIOSOS: NOVAS SINGULARIDADES NA SOCIEDADE DE CONSUMO
}

\author{
MEGA-EVENTS AND RELIGIOUS SPECTACLES: \\ NEW SINGULARITIES WITHIN THE CONSUPTION SOCIETY \\ MEGA-EVENTOS Y ESPECTÁCULOS RELIGIOSOS: \\ NUEVAS SINGULARIDADES EN LA SOCIEDAD DE CONSUMO
}
Karla Patriota Bronsztein
Dra, UFPE
k.patriota@gmail.com

Maria Lúcia Bastos Alves

Dra, UFRN

mluciabastos29@yahoo.com.br

\section{Resumo}

O artigo propõe apresentar uma análise de dois eventos religiosos de grande repercussão na mídia impressa e eletrônica como forma de novas demandas de consumo. Trata-se de uma reflexão que estuda o fenômeno religioso contemporâneo, no qual as práticas religiosas ganham maior visibilidade nos meios de comunicação de massa e são redefinidas numa sociedade de cunho espetacular, evidenciando como as identidades religiosas se mostram cada vez mais influenciadas pela mídia, reformuladas segundo as regras próprias do espetáculo (show business) e da indústria do entretenimento. A análise do fenômeno é feita com base na observação da "Marcha para Jesus" em Recife-PE, festa interdenominacional e internacional de base evangélica e dos "showmissas" produzidos por representantes da Igreja Católica em Natal-RN. A pesquisa desenvolvida revela que tais eventos ao se tornarem produtos culturais, negociam suas singularidades em consonância com efeitos midiáticos e reações que provocam nos seus participantes, contribuindo para a padronização de comportamentos impostos pela atual sociedade de consumo.

Palavras-Chave: Espetáculo religioso; mídia; Sociedade de Consumo; Showmissa; Marcha para Jesus.

\begin{abstract}
The article aims to present an analysis of two religious events are highly influential in print and electronic media as a form of new consumer demands. This is a reflection that studies religious phenomena, in which religious practices have gained greater visibility in the media and mass are redefined in a society of spectacular nature. It highlights how religious identities are becoming increasingly influenced by the media, reformulated according to the rules of the spectacle (show business) and entertainment industry. The analysis of the phenomenon is based on observation of the "March for Jesus" in Recife-PE, party interdenominational and international evangelical base and "show masses" produced by
\end{abstract}


representatives of the Catholic Church in Natal, Brazil. The research undertaken shows that such events become cultural products negotiate in line with its singular media effects and reactions that lead to its participants, contributing to the standardization of conduct imposed by the current consumer society.

Keywords: Religious spectacle; media; Consumer Society; show mass; March for Jesus.

\section{Resumen}

El artículo tiene como objetivo presentar un análisis de dos acontecimientos religiosos de gran repercusión en los medios impresos y electrónicos como forma de nuevas demandas de consumo. Es una reflexión que estudia el fenómeno religioso contemporáneo, donde las prácticas religiosas obtienen una mayor visibilidad en los medios de comunicación y son redefinidas en una sociedad de naturaleza espectacular, demostrando cómo las identidades religiosas se presentan cada vez más influenciadas por los medios de comunicación y reformuladas de acuerdo con las propias normas de la industria de espectáculo y el entretenimiento. El análisis de los fenómenos se basa en la observación de la "Marcha para Jesús" en Recife-PE (Brasil), del partido y de la base evangélica interdenominacional internacional y de las "showmissas" producidas por los representantes de la Iglesia Católica en Natal-RN. La investigación revela que cuando estos eventos se convierten en productos culturales, pasan a tener sus singularidades de acuerdo con los efectos que los medios comunicación y las reacciones provocan en sus participantes, contribuyendo con la normalización de la conducta impuesta por la sociedad de consumo actual.

Palabras clave: medios de comunicación religiosos, espectáculo, la sociedad de consumo; showmissa; Marcha para Jesús.

\section{Introdução}

Em diferentes épocas e contextos socioculturais a religião tornou-se uma marca indelével na história da humanidade. É impossível negar a contribuição do cristianismo na organização e formação cultural das sociedades ocidentais. Peregrinações, cultos, ritos, participação em grupos comunitários e em movimentos de grande mobilização atestam a relevância de comportamentos e práticas religiosas na vida de inúmeras pessoas. No Brasil as estatísticas mostram que uma grande parcela da população declara professar alguma religião ${ }^{1}$. O que se pode inferir que as ações cotidianas, dessa população, são regidas por valores religiosos, morais e éticos conforme a religião que se professa.

No âmbito dessa perspectiva, em que a vivência religiosa se faz presente nos lares, nas ruas, no trabalho e na vida social de modo geral, interessa abordar a mídia ${ }^{2}$, enquanto

\footnotetext{
1 De acordo com o Censo de 2000, por exemplo, 73,8\% dos brasileiros se declaram católicos e $15,4 \%$ evangélicos (os sem religião revelaram 7,3\% de autodeclaração) - os 3,5\% restantes do percentual total da população confessa todas as outras modalidades religiosas, que não as católicas e evangélicas. Contudo, há nos dados divulgados uma grande a quantidade de outras religiões citadas pelos entrevistados, e o Censo as discerne nominalmente, mas nelas se congregam populações muito pequenas, para não dizer ínfimas. (PIERUCCI, 2006, p. 50).

2 De acordo com Dowining (2002) mídia são processos comunicacionais realizados por meio de um complexo intrincado de interesses, demandas e respostas conflituosas formadas por forças díspares que envolvem 
formadora de novos hábitos e estilos de vida. Isto é, como os meios de comunicação de massa $^{3}$ são capazes de ressignificar e re-dimensionar os ritos e as práticas religiosas como produto de consumo. Seja como fonte de entretenimento, instrumento de adesão/conversão e/ou formadoras de opiniões, as imagens e mensagens religiosas veiculadas na mídia convidam a participar e experimentar sentimentos de apoio ou de repulsa diante dos acontecimentos.

Em se tratando de um campo religioso brasileiro plural e competitivo, a mídia, cada vez mais, se faz presente na divulgação e na formação das identidades religiosas na medida em que se multiplicam as demandas e possibilidades de mudanças de credos. Em outras palavras, as instituições religiosas ao perderem o controle dos anseios individuais recorrem à mídia $^{4}$ para recuperar e/ou ampliar o contato com a sociedade e investem na prospecção religiosa dos indivíduos.

Se outrora a formação religiosa era de responsabilidade da família e a oração contrita e individual posicionava o fiel no recinto do templo sagrado ou mesmo diante do oratório familiar, hoje os diversos meios de comunicação atingem, indistintamente, vários públicos possibilitando a formação e a construção de peculiares identidades religiosas. A televisão e a internet, de forma exemplar na contemporaneidade, tornaram-se duas das principais vitrines da Sociedade de Consumo ${ }^{5}$, sacralizando os espaços em que se encontram, fazendo a

negociações com os sujeitos representados e os públicos destinatários. Considera-se aqui, os meios de comunicação massiva e seus diversos veículos: tevês, rádios, jornais, revistas e internet.

${ }^{3}$ Os Meios de Comunicação de massa ampliaram o espectro de receptores. São fundamentais para a convivência, a coabitação em sociedades multiculturais. Representam uma condição para a democracia ao assegurarem o laço social, o pluralismo e a capacidade mobilizadora de todos os públicos simultaneamente (WOLTON, 2006).

${ }^{4}$ Prova disto é a imensa quantidade de programas religiosos televisivos, tanto na TV aberta, como em UHF, ou mesmo em TV por assinatura. Praticamente todas as ramificações religiosas buscam um espaço na televisão sejam em canais próprios (TV Aparecida, Rede Boas Novas, TV Canção Nova, RIT, Rede 21, Rede Gospel, Rede Vida, TV Século 21, Canal da Juventude Cristã, TV Igreja Mundial, MTV Mundo Maior, Rede Gênesis, Rede Super, STV Novo Tempo, TV Setorial) até atrações na Rede TV Gazeta, CNT e Bandeirantes, inclusive no horário tido por "nobre".

${ }^{5}$ Para diversos estudiosos como Frederic Jameson, Jean Baudrillard e Zygman Bauman a cultura do consumo é a cultura em vigor na sociedade pós-moderna ou do capitalismo tardio e a crítica social se torna o foco de seus trabalhos. Uma série de atributos negativos é relacionada, desde o século XVII até os dias de hoje, ao ato de consumir: perda da autenticidade, materialismo, exclusão, hedonismo e superficialidade, entre outros, permeando discursos de cunho moral e moralizantes sobre os efeitos do consumo nas sociedades contemporâneas. O sociólogo polonês Zygmunt Bauman tornou-se conhecido por suas análises das ligações entre a modernidade e o holocausto, e o consumismo pós-moderno. A Cultura Consumista é o seu objeto de estudo em diversos escritos no quais aborda os efeitos que a atual estrutura social e econômica, baseada na Sociedade de Consumo, provoca nas diversas esferas da vida das pessoas. Bauman (2008) também avalia quais os efeitos da troca da anterior Sociedade de Produtores, que define como moderna e sólida, pela Sociedade de Consumidores, denominada como pós-moderna e líquida. Na Sociedade de Produtores os bens eram resistentes, a satisfação parecia residir na promessa de segurança em longo prazo e o consumo excessivo era mal visto; já na Sociedade de Consumidores, a transformação dos desejos humanos de estabilidade e saciedade se faz necessária e a felicidade desvincula-se da ideia de satisfação das necessidades e passa a ser associada a um volume e intensidade de desejos sem fim - o que implica um estado de troca permanente. 
mediação e permitindo que os fiéis participem dos diversos ministérios e serviços disponíveis: assistam missas, façam novenas ao santo protetor, rezem o terço, recebam a benção em copos com água postos em frente à tevê, acendam velas virtuais, entre outras práticas religiosas.

Assim, a propagação da religião midiática se revela não apenas na livre escolha, por parte dos indivíduos, da filiação religiosa que lhes pareça melhor ${ }^{6}$, mas também nos contornos do agente religioso, que agora necessita empreender um maior esforço pela manutenção e conquista dos fiéis, uma vez que não dispõe mais de uma clientela permanentemente constituída. Igrejas católicas, evangélicas, reformadas ou "renovadas" promovem eventos que contabilizam multidões com ampla repercussão nos diversos veículos de comunicação.

A cada dia a exposição das crenças passa a ser vista como instrumento de aprovação e comprovação existencial. Milhares de pessoas buscam encontrar um espaço nos meios de comunicação para relatarem suas histórias ou darem testemunhos de fé. Líderes e seguidores de confissões religiosas vêem na exposição midiática a possibilidade de se afirmarem enquanto atores sociais e merecedores de um lugar de destaque na vida comunitária e social. A visibilidade da identidade religiosa passa a ser sinônimo de reconhecimento e legitimidade daquilo que se considera aprovável e exemplar. Klein (2006) afirma que a religiosidade contemporânea cedeu à sedução midiática. Segundo o autor, mesmo o protestantismo que primava pela defesa da Palavra, tem permitido que o sagrado se aparte do austero discurso presente nos sermões de outrora e migre para o espetáculo das imagens.

Nesse cenário, atores e espectadores se colocam, ao mesmo tempo, como produtos e produtores de uma sociedade na qual o principal alicerce é o consumo. Ou seja, as instituições religiosas e midiáticas apresentam-se não só como fabricantes e promotores de comportamentos e atitudes, mas, também, como campo de atuação dos sujeitos na busca de afirmação e legitimação de novas identidades coletivas e individuais. Isso pode ser observado no que atesta Stuart Haal (2005, p. 75), ao dizer que quanto mais à vida social se torna mediada pelo mercado global de estilos, lugares e imagens, pelas viagens internacionais, pelas imagens da mídia e pelos sistemas de comunicação globalmente interligados, mais as identidades se tornam desvinculadas - desalojadas - de tempos, lugares, histórias e tradições específicas e parecem “flutuar livremente". Isto é, a mídia reordenou o espaço e o tempo no

\footnotetext{
${ }^{6}$ Segundo Hervieu-Léger (1999) esta construção individual de uma religiosidade "customizada" de contornos próprios e totalmente autônoma, tem sido chamada de "bricolagem", ou simplesmente: uma religiosidade do "faça você mesmo".
} 
mundo moderno por meio da hibridização das novas tecnologias, proporcionando novas possibilidades comunicativas e a consequente criação de um novo ethos.

.O fato é que vivemos em uma sociedade com forte ênfase midiática, na qual as imagens desfrutam de um lugar privilegiado. Parece mesmo que tudo ao nosso redor, inclusive os postulados religiosos, solicita a mediação das mídias, sejam elas mídias massivas ou não, já que o crescente acesso aos meios tecnológicos pessoais como computadores, ipods, tablets e telefones celulares contribuem, ainda mais, para o aumento na avalanche visual personalizada dos conteúdos disponíveis.

Nessa abundante exposição midiática, os mega-eventos marcam presença em diferentes contextos sociais e geográficos disseminando imagens e transformando as celebrações em espetáculos a serem consumidos. Não é por acaso que as celebrações religiosas de grande impacto realizam seus eventos em estádios de futebol, nas principias avenidas, praças, ou outros locais de grande visibilidade, visto que tais espaços se tornaram espaços midiáticos (CANCLINI, 1997).

Inseridos nesse cenário encontram-se a Marcha para Jesus, festa interdenominacional e internacional de base evangélica e os "showmissas" produzidos por representantes da Igreja Católica, liderados pelos "padres cantores". Eventos que, tendo como característica principal a participação de milhares de pessoas, tem como suportes uma profusa cobertura midiática e um amplo impacto no social. Na intenção de analisar a atuação e influência da mídia nos referidos eventos, escolheu-se como campo de estudo as versões de 2008, 2009 e 2010 de dois mega-eventos religiosos, um de vertente católica e outro de cunho evangélico: as Marchas para Jesus (ocorridas na cidade do Recife-PE) e os showmissas do Padre Fábio de Melo (realizados na cidade de Natal-RN).

\section{Cantando ou marchando: Mídia e religiosidade}

A temática mídia e religião têm suscitado reflexões em diferentes áreas de pesquisas. No Brasil, o campo religioso tornou-se foco de estudo entre pesquisadores como Hugo Assmann (1986); Paul Freston (1993); Antonio Pierruci e Reginaldo Prandi (1996) Alexandre B. Fonseca (1997); Leonildo Silveira Campos (1997); Antonio Gouveia Mendonça (2005), entre outros que trazem proveitosas contribuições para os estudos da mídia e religião nas diversas esferas sociais, particularmente na esfera política.

Influenciado pelo modelo norte-americano, o protestantismo histórico, o pentecostalismo e suas diferentes denominações registram a presença na mídia não somente 
como divulgadora de um determinado segmento religioso, mas, também como fonte de interação entre os fiéis e construção de novas identidades religiosas ${ }^{7}$. Todavia, é com o surgimento da IURD (Igreja Universal do Reino de Deus ${ }^{8}$ ), principal expoente do movimento neopentecostal no Brasil, e a sua notória presença nos principais veículos de comunicação, que as pesquisas sobre religião e mídia ganham destaque tanto no campo religioso quanto no cenário midiático. Em 1989 esta igreja tornou-se proprietária da Rede Record de Televisão e, seguindo os padrões empresariais, soube fazer uso dos variados meios de comunicação de massa não só apostando na disputa por novos adeptos como também transformando a comunicação religiosa num negócio rentável ${ }^{9}$.

Hoje, diversas igrejas cristãs, católicas, reformadas ou "renovadas" investem em mega-eventos e ampliam sua aparição na mídia - o que resulta em consideráveis multidões nos mesmos. A sociedade contemporânea, com a sua proeminência midiática, viabiliza a produção/divulgação de mega-eventos religiosos pelas grandes redes de televisão nas quais há a participação de estrelas do "God's pop". Da perspectiva das instituições denominacionais, tal exposição religiosa, em seus diversos tipos de manifestação, é, como esclarece Gomes (2008, p.55), ao mesmo tempo, "forma de legitimação e estratégia de visibilização". Para a autora, tal postura é decisiva para a reflexão sobre determinadas manifestações contemporâneas, aparelhadas por instituições religiosas com a intenção de ajuntamento de milhares de pessoas.

No caso da Igreja Católica, que mesmo tendo investido nos meios de comunicação há mais tempo, somente nos anos 1980 passou a utilizar a mídia de forma mais ostensiva, provavelmente porque nessa época os dados censitários começaram a indicar uma perda considerável de fiéis ${ }^{10}$. Ao contrário da constituição Inter multiplices, ${ }^{11}$ documento oficial da

\footnotetext{
${ }^{7}$ De acordo com Leonildo Silveira Campos (....) a relação entre evangélicos e mídia no Brasil data de 1940 quando surgiram os primeiros programas evangélicos no rádio. Entre as igrejas que se faziam presente destacase a Igreja Adventista, a Assembléia de Deus, a Igreja do Evangelho Quadrangular, O Brasil Para Cristo e a Igreja Deus é Amor. Maiores informações sobre a presença da mídia no campo evangélico consultar L. S. CAMPOS, Protestantismo brasileiro. 2004, pp.125-126.

${ }^{8}$ A Igreja Universal do Reino de Deus tem apresentado um crescimento surpreendente no Brasil, principalmente se considerarmos o pouco tempo de existência (o seu surgimento data o ano de 1977). A taxa de crescimento anual dos iurdianos é de $25,7 \%$, quase três vezes superior à do grupo de pentecostais brasileiros.

${ }^{9}$ Atualmente a IURD está presente em mais de 80 países da América, Europa, Ásia e África. No Brasil, além da rede de TV Record, é detentora de rádio, jornal, revista, editora, gravadora, portal na Internet.

${ }^{10}$ As peculiaridades de um Brasil religioso, cada vez menos católico, não são reveladas da noite para o dia. É verdade que tais variações são observadas de forma mais palpável depois de 1980, todavia, o movimento de redução do catolicismo está ocorrendo de forma significativa pelo menos desde a década de 40, nos fazendo refletir qual é o conjunto de fatores fundamentalmente desencadeadores da instauração do processo de "descatolização" brasileira.

11 Primeiro documento oficial da Igreja Católica sobre a imprensa, elaborado em 1487 no Pontificado do Papa Inocêncio VIII. Esse documento evidencia o caráter proibitivo, insistindo na autoridade da Igreja sobre o 
Igreja Católica elaborado no pontificado do papa Inocêncio VIII no século XV, que afirmava ser a mídia responsável por divulgar idéias contrárias à fé e aos bons costumes difundidos, hoje, após um longo período de críticas e diálogos com os meios de comunicação, a Igreja Católica defende a utilização desses como recurso de fundamental importância para a evangelização e difusão das suas crenças. Inclusive, tendo o Papa João Paulo II, em sua encíclica Redemptoris Missio, afirmado que a mídia é o Areópago ${ }^{12}$ dos tempos modernos, ou seja, local ideal para o anúncio e a proclamação da fé católica.

Sob esta visão e detentora de um conglomerado midiático que abrange três emissoras de televisão: Canção Nova, Rede Vida, Século XXI, além de editora de livros, revistas, jornais, internet e centenas de emissoras de rádios espalhadas pelo país, esta instituição não só investe nos jovens "padres cantores" como estratégia para a propagação da religião católica, na luta contra a adesão a outras instituições religiosas, especialmente ao neopentecostalismo ${ }^{13}$, como também aposta no desenvolvimento de suas atividades econômicas, uma vez que o crescimento das vendas de produtos religiosos é um dos setores mais rentáveis.

Estudos como o de Brenda Carranza (2000) e André Ricardo de Souza (2005) demonstram como catolicismo midiático tem sido hábil na concorrência pelo mercado religioso, especialmente após o surgimento da Renovação Carismática Católica - RCC que, com rituais de celebração semelhante às práticas do neopentecostalismo, apropria-se da cultura midiática através do uso religioso dos meios de comunicação de massa com o intuito de adaptar-se aos novos tempos. De acordo com Carranza (2000) a ascensão do Padre Marcelo Rossi ${ }^{14}$ nas emissoras de rádio, televisão, internet e cinema representa mais um

conhecimento. Maiores informações consultar, PUNTEL, Joana T. A Igreja e a democratização da comunicação. S. Paulo: Paulinas, 1994.

${ }^{12}$ De acordo com Atos 17:16-33, Paulo fez um discurso no Aerópago, chamando os atenienses da idolatria para o culto ao Deus verdadeiro (o Deus do Cristianismo).

${ }^{13}$ Nome que se dá aos pentecostais da terceira geração. Diversos autores os têm designado de maneiras diversas, entretanto neste trabalho assim os chamamos, porque é possível perceber que eles diferem muito dos pentecostais históricos e dos da segunda geração. Dessa forma, semelhantemente a Mariano (1995), acreditamos tratar-se realmente de um novo pentecostalismo: (...) "termo que mais vem ganhando terreno nos últimos anos entre os pesquisadores brasileiros para classificar as novas igrejas pentecostais. Embora recente entre nós, o termo foi cunhado há vários anos nos Estados Unidos" (MARIANO, 1995, p. 25). Afinal, esses novos crentes não mais se preocupam com as limitações que possam ser impostas ao tipo de vestuário ou de costumes, e muito embora ainda creiam no dualismo do mundo espiritual, falam de Deus de forma extremamente diferente de seus antecessores.

${ }^{14}$ Sacerdote católico brasileiro que se transformou em um fenômeno de mídia e cultura de massas no final dos anos 90. Ganhou fama pela forma como adota danças e coreografias típicas da RCC e pela publicidade dos trabalhos (CDs, DVDs, livros, cinema e televisão). Cantando, dançando e fazendo coreografias em missas lotadas e programas de televisão, se propõe a levar aos homens a mensagem e os ensinamentos da Igreja de uma maneira original, leve, moderna. Já gravou vários discos, escreveu livros, fez cinema, tem programa de rádio e TV e aparece constantemente em programas seculares de tevê ao lado de estrelas do show business. 
exemplo da cultura de consumo configurada nos imaginários, subjetividades e sociabilidades religiosas.

Em Igreja in concert: padres cantores, midia e marketing, Souza (2005) analisa o sucesso e a popularidade que os "padres cantores" inseridos na grande mídia eletrônica e televisiva tem adquirido entre os fiéis das diversas classes sociais. Estes, nacionalmente reconhecidos e assediados por grupos de fiéis e telespectadores, tornam-se verdadeiros showmans, contribuindo para um novo tipo de evangelização e assegurando a audiência das emissoras. Para o referido autor, o marketing religioso católico, frente a um pluralismo religioso competitivo, justifica a sua advertência de que "a música exerce um papel importante na atual propagação das denominações religiosas, sobretudo no segmento juvenil" (2005, p.10).

É justamente neste ponto "musical" que vemos o amplo imbricamento das religiosidades católicas e evangélicas. Ambos os eventos, alvos do nosso estudo, são alicerçados no seu caráter musical. Isso fica-nos claro quando as igrejas não mais são restritas aos templos, mas abertas a toda sociedade com atos musicais e artísticos como expressões públicas de fé. Na Marcha para Jesus, por exemplo, são milhares de cristãos marchando pelas ruas, de todas as idades, raças, nacionalidades e culturas étnicas. Roupas coloridas, bandeiras, faixas, galhardetes e outros adereços são usados. Como parte do calendário oficial de diversas cidades, a Marcha conta com a participação de trios elétricos com muitos cantores de diversas comunidades e igrejas cristãs, envolvendo todas as denominações ${ }^{15}$.

Parece-nos ocorrer na Marcha para Jesus a clara concretização do que Cunha (2007) assinala quando aborda as composições gospel $^{16}$, ressaltando a capacidade que tais músicas têm de juntar tradição com modernidade, fazendo aflorar o que a autora intitula de "hibridismo cultural", que instaura a possibilidade dos cruzamentos, inter-relações, mestiçagens e sincretismo entre o erudito e o popular, o moderno e o tradicional e que foi permitido com o desenvolvimento das tecnologias de massa (CUNHA, 2007, p.23). O que também é, notadamente, evidenciado com as composições da Igreja Católica, atualmente veiculadas na mídia através dos shows de seus padres cantores. Concedendo boa parte de suas

\footnotetext{
${ }^{15}$ São Paulo é a cidade onde ocorre a maior Marcha do mundo - centenas de cidades também realizam o evento, levando milhares de pessoas para as ruas do Brasil. (Fonte: site oficial da Marcha para Jesus: http://www.marchaparajesus.com.br/, consultado em 27.01.08).

${ }^{16}$ Conforme Dolghie (2004), tais composições possuem grande liberdade estilística e de aproximação com o modelo de bandas seculares (não religiosas) - o que possibilita uma apropriação de elementos culturais e confere certo status social ao grupo de produtores e consumidores, os evangélicos do país. A autora ainda defende que o nome gospel foi uma eficiente estratégia de marketing para dar visibilidade à religiosidade evangélica, bem como ao seu próprio produto.
} 
análises ao desempenho e sucesso do Padre Marcelo Rossi, Souza (2005) evidencia que a performance desse padre não só motivou outros "padres cantores" consagrados na mídia e no meio artístico, a exemplo do Padre Zeca e Padre João Maria, como também tem influenciado os novos seminaristas em sua carreira eclesiástica. Suas missas, embaladas por muitas músicas, danças e coreografias, transformam-se num show musical, verdadeiro espetáculo que, muitas vezes, provoca polêmicas entre clérigos e adeptos de outras instituições religiosas.

Em meio a esse cenário, católico artístico e midiático, destaca-se o sucesso do Padre Fábio de $\mathrm{Melo}^{17}$ que, tendo como referencial o Padre Zezinho ${ }^{18}$, tornou-se um dos grandes ícones de vendas do mercado editorial e fonográfico. Entre as suas gravações encontra-se a participação de consagrados cantores da Música Popular Brasileira a exemplo de artistas como Toquinho, Fábio Júnior e Renato Teixeira.

De acordo com a revista Veja ${ }^{19}$, "o fenômeno Fábio de Melo leva essa aproximação com o universo mundano a um extremo inédito", destacando-se entre os maiores recordistas de vendas de CDs no Brasil ${ }^{20}$. Sua notável posição no ranking do mercado editorial e fonográfico impulsiona milhares de fiéis a assistirem seus showsmissas, considerados pela mídia como mega-eventos religiosos.

\section{Os showsmissas e a participação do Padre Fábio de Melo em Natal/RN}

O nosso corpus de pesquisa contempla, especificamente, um evento religioso de vertente católica: três shows-missas que marcaram a participação do Padre Fábio de Melo em Natal/RN, com grande propagação publicitária e noticiosa e muitas polêmicas na mídia.

O primeiro em 22 de novembro de 2008, realizado no Ginásio de Esporte

\footnotetext{
${ }^{17}$ Que se tornou nacionalmente conhecido por seu trabalho como comunicador, com vários livros e CDs publicados, além de apresentar um programa transmitido pela Canção Nova.

${ }^{18}$ Pe Zezinho destaca-se entre os primeiros clérigos a fazerem sucessos na mídia fonográfica e editoria, ainda na década de 1960. Membro da congregação Sagrado Coração de Jesus e Diocese de Taubaté em São Paulo, este padre além de cantor é também escritor e apresentador do Programa Direção Espiritual, transmitido semanalmente pela rede de TV Canção Nova. Possui um estilo jovem e apresenta-se com roupas de grifes sob um físico moldado por exercícios. De voz baixa e calma atrai muitos fãs, em sua maioria, do sexo feminino.

${ }^{19}$ Edição 2098, de 4 de fevereiro de 2009.

${ }^{20}$ Até 2011 eram ao todo 23 CDs: Iluminar (ao vivo); Iluminar; Grandes momentos 2; Eu e o Tempo; Kit Eu e o Tempo; Coletânea Padre Fábio de Melo - 3 CDs; Vida; Enredos do Meu Povo Simples; Grandes Momentos; Enredados - Volume 2; Enredados - Volume 1; Cristão; Filho do Céu; Sou um Zé da Silva e outros tantos; Tom de Minas; Humano Demais; Marcas do Eterno; Saudades do Céu; As Estações da Vida; Canta Coração; De Deus Um Cantador. 8 Livros: Cartas entre Amigos: Sobre Ganhar e Perder; Mulheres Cheias de Graça; Cartas entre Amigos - Sobre Medos Contemporâneos; Quando o sofrimento bater à sua porta; Mulheres de aço e de flores; Quem Me Roubou de Mim?; Amigos somos muitos, mesmo sendo dois; Tempo: saudades e esquecimentos. 1 DVD: Bem da Palavra do Bem, disponíveis para comercialização em lojas e no site no Padre.
} 
Machadinho $^{21}$, com ingressos que variavam de $\mathrm{R} \$ 15,00$ a $\mathrm{R} \$ 35,00$. Na ocasião o padre lançou o seu novo CD intitulado Vida. O segundo, em 25 de julho de 2009, realizou-se no estádio de futebol Machadão ${ }^{22}$ onde apresentou músicas do CD e DVD Eu e o Tempo para um público estimado em 18.000 pessoas, que pagaram ingressos entre $R \$ 20,00$ e $R \$ 40,00$. O terceiro, ocorrido no Colégio Católico Salesiano, em 26 de novembro de 2010, por ocasião das festividades da padroeira da cidade de Natal, foi notadamente diferente em relação aos shows anteriores, visto que a estimativa de público foi de "apenas" 1.800 pessoas. Na oportunidade, o padre aproveitou para lançar o CD e DVD Iluminar. A venda dos ingressos disponíveis na Rádio Rural, Livraria Canção Nova e na livraria da Arquidiocese giraram em torno de R\$ 40,00 a R\$ 120,00. De acordo com a organização da Canção Nova, a renda foi revertida para as obras de reforma e compra de equipamentos para a Arquidiocese de Natal.

Nos três momentos listados percebemos vivências religiosas alicerçadas na religiosidade contemporânea, que se acomodou e dialogou com o espaço público, deixando de lado uma fé menos intimista, tornando-a cada vez mais visível. Logo, os showsmissas se transformaram em expressões religiosas da atualidade que passaram, justamente, a compor a nossa sociedade contemporânea, marcadamente mercadológica, pautada pelo consumo e de essência espetacular. Este fato é respaldado pela ampla cobertura midiática dada aos citados eventos nos principais jornais estaduais, rádios e tevês, mas, principalmente, pela participação pagante de muitos fiéis nos shows do Padre Fábio e da venda de mais de 2 milhões de cópias de CDs (1,8 milhão apenas pela gravadora Som Livre), além de 500 mil exemplares dos livros produzidos pelo padre.

Contudo, mesmo que a igrejas contemporâneas dialoguem com os consumidores religiosos como agentes sociais e legalmente reconhecidos nas transações econômicas, também pudemos verificar o quanto é incômoda a revelação desse contexto mercadológico no cenário religioso. Prova disso foi justamente a última versão do evento que estudamos, que não atingiu os índices de público estimados em relação aos eventos anteriores. Tal fato se explica pela resposta dada às polêmicas veiculadas na mídia impressa e televisiva em relação ao mega-evento de 2009, ocorrido no Estádio de Futebol Machadão e promovido pela Arquidiocese de Natal, em conjunto com a Prefeitura de Natal, em homenagem aos 410 anos

\footnotetext{
${ }^{21}$ Situado ao lado do Machadão, o ginásio poliesportivo Humberto Nesi ficou conhecido como Machadinho e possui capacidade para 12 mil pessoas.

${ }^{22}$ O Estádio João Cláudio de Vasconcelos Machado, conhecido como Machadão, é o principal e maior estádio de futebol da cidade do Natal e do estado brasileiro do Rio Grande do Norte, com capacidade para 35.000 espectadores.
} 
da cidade e 100 anos da Arquidiocese de Natal.

No que diz respeito ao evento de 2009 , considerado o maior showmissa desse padre na cidade de Natal, as repercussões midiáticas suscitaram polêmicas entre fiéis, religiosos, mídia, empresários e políticos locais, os quais, manifestando suas opiniões nos meios de comunicação, criticavam o valor de $\mathrm{R} \$ 221.000,00$ (duzentos e vinte e um mil reais) pagos como cachê artístico e custeados pelos cofres municipais. A repercussão na imprensa foi imediata e a reação do público expressava insatisfação. Tanto dos fiéis, que estranharam o valor do cachê, como também de autoridades eclesiásticas como o arcebispo de Natal, Dom Matias Patrício de Macedo, que afirmou publicamente que a Arquidiocese apenas se "associou" ao evento já contratado para realização do encerramento das festas natalinas em Natal - o que incluiu a missa e a abertura do Congresso Eucarístico Missionário - CEMAR.

O imbróglio sobre o valor do cachê girou em torno do cancelamento da turnê nordestina do referido padre nas cidades de Fortaleza (CE) e João Pessoa (PB) em que as despesas deveriam ser divididas com a cidade de Natal. Diante desse impasse e com o objetivo de evitar o cancelamento do showmissa em Natal, a prefeita da cidade, Micarla de Sousa, contratou uma empresa para realizar do evento. Duramente criticada na mídia pelo público em geral, a Prefeitura de Natal emitiu uma nota oficial explicando o valor do contrato do show do Padre Fábio de Melo e esclarecendo que nele estavam inclusos valores de salários, diárias e despesas de alimentação de uma equipe com cerca de 25 pessoas, com valores de passagem aérea para a maioria delas, valores para fretamento de avião para trazer parte dos músicos, valores de hospedagem de todos os profissionais, valores do transporte para profissionais e equipamentos de som e luz que acompanham o show. É provável que se o evento em questão fosse de caráter meramente secular, não houvesse suscitado tanto desconforto entre os envolvidos: o próprio Fábio de Melo (que se defendeu publicamente tanto na mídia eletrônica e impressa, como no seu site pessoal ${ }^{23}$ e no Twitter ${ }^{24}$ ), o público em geral, os fiéis católicos, a Arquidiocese, a Prefeitura de Natal e a grande mídia, que noticiou amplamente todos os detalhes das trocas de acusações e defesas de pontos de vista.

Polêmicas a parte, o que se discute aqui é a capacidade imediata da mídia em (re) produzir informações e contribuir para o surgimento de um hedonismo socializado a ponto de construir a "Sociedade do Espetáculo" compreendida por Guy Debord, (1997, p. 10) "não como um conjunto de imagens, mas uma relação social entre pessoas, midiatizada por imagens (...) e que se constitui o modelo presente da vida socialmente dominante”. O próprio

\footnotetext{
${ }^{23} \mathrm{http}: / /$ www.fabiodemelo.com.br/

${ }^{24} \mathrm{http}: / /$ twitter.com/pefabiodemelo (que na época deste trabalho contava com 219,655 seguidores)
} 
Padre Fábio, em uma entrevista concedida à Marília Gabriela em 2009, comentou essa íntima relação da mídia com as imagens e como se sentiu exposto nessa relação social mediada pelos meios de comunicação massivos. Nessa entrevista ele afirmou que foi "perseguido" pela imprensa no início da carreira. "A mídia foi muito cruel quando eu apareci. É muito triste ser reduzido a uma imagem. A mídia me expõe como um homem vaidoso".

A visibilidade e repercussão dos mega-eventos religiosos na mídia atingem seu mais alto grau, não só por meio dos comentários e repercussões causados no social, mas principalmente pelos efeitos imagéticos e sonoros que compõe os cenários. Nos shows do Padre Fábio, nos momentos de êxtase, na exposição dos cantos e nas orações, há a transformação, pela na mídia, dos postulados religiosos em produtos de consumo sem, necessariamente, possibilitar reflexão sobre os valores por eles disseminados. Assim sendo, como argumentam Dolghie e Campos (2010, p.4), "antes de se compreender a religião e sua produção simbólica como espetáculo, é fundamental passar analiticamente pela fase imediatamente anterior, que é a das produções religiosas como mercadoria”.

Contrário as ideias dos teóricos "pessimistas" a exemplo de Adorno e Horkheimer (1986) os quais ressaltam o poder demoníaco midiático na sua capacidade de seduzir as massas e disseminar visões de mundo estereotipadas, Gianni Vattimo (1992) ressalta o inegável papel da difusão e propagação dos meios de comunicação de massa no desenvolvimento da sociedade contemporânea. Para o referido autor, o jornal, o rádio, a televisão e as novas tecnologias contribuíram para a dissolução dos pontos de vista centrais, pulverizando as grandes narrativas. Alerta para a necessidade de olhar para outro aspecto da difusão midiática, isto é, a possibilidade dela construir múltiplas visões de mundo contribuindo para valorização das diferenças e as transformações sociais.

Neste cenário, onde a mídia difunde visões de mundo e os códigos de comportamento são institucionalizados e propagados, decorre a fragmentação das práticas religiosas tradicionais e a criação de outras possibilidades para as novas práticas. É assim com o catolicismo da contemporaneidade que, utilizando fortemente o caráter propagador da mídia, lança mão de padres cantores e missas regadas pelo espetáculo de luzes e sons. Corroborando com essa linha de raciocínio, Thompson (2002) enfatiza a positividade da mídia como um meio de apropriação das diferentes formas simbólicas de representação cultural que cria um novo tipo de publicidade, denominada como o "espaço do visível" 25 . Para o autor, o caráter

\footnotetext{
25 Trata-se de um espaço não localizado, não dialógico e aberto, no qual as formas simbólicas mediadas podem ser produzidas e recebidas por uma pluralidade de outros sujeitos não presentes (THOMPSON, 2002, p. 113). 
identificador da tradição, paulatinamente, é remodelado - em parte pela mídia - e relativizado a uma crescente autonomia do indivíduo como agente capaz de refazer a própria identidade, o que explica a persistência de crenças e práticas religiosas no mundo moderno. Segundo Thompson (2002, p. 171-172), "a manutenção da tradição no tempo exige uma continua reconstituição de seu conteúdo simbólico nas atividades cotidianas. [...] Com a fixação do conteúdo simbólico da tradição nos produtos da mídia, esta tornou-se desritualizada". Ainda de acordo com o autor, as práticas tradicionais não desapareceram sob ação das mídias, elas foram renovadas em outros referenciais simbólicos.

$\mathrm{Ou}$ seja, ao analisarmos mega-eventos com os showmissas, concluímos que o consumo cultural se dá a partir de uma remodelação que transforma os produtos culturais em espetáculos a serem consumidos, espetáculos estes produzidos por meio do "profícuo" imbricamento com as práticas seculares mercadológicas. O campo da produção e do consumo da cultura, portanto, é ressignificado e muitos conteúdos religiosos, antes considerados ultrapassados, são transformados em novos elementos de consumo.

\section{A Marcha para Jesus em Recife-PE}

A proposta institucional da Marcha para Jesus é ser um evento internacional e interdenominacional que ocorre anualmente em milhares de cidades do mundo. Mesmo apresentando uma impressionante participação de pessoas no país, a Marcha não teve sua origem em terras brasileiras. Segundo Mendes (2008) seus fundadores são Roger Forster (pastor), Graham Kendrick (cantor e compositor), Gerald Coates e Lynn Green, com a primeira edição realizada em 1987, em Londres. Foi apenas a partir dos anos 1990 que a Marcha se estendeu pelos países da Europa, Américas, África e Ásia, sendo transformado em um evento de escala mundial, com a intenção de ser um ato pacífico, consciente do "mover de Deus"26.

Em 1994 foi realizada a primeira versão global do evento, alcançando 170 países com a presença de 10 milhões de participantes. Uma nova versão global da "marcha" aconteceu em 10 de junho de 2000. Desde então, o grupo organizador original se dispersou e a organização do evento tem ocorrido por parte de iniciativas locais e em datas distintas.

Apesar de ter tido sua inspiração na cultura européia e constituir-se, inicialmente, como uma marcha tradicional, aqui no Brasil a Marcha logo incorporou a diversidade dos nossos ritmos musicais. Siepierski (2001) esclarece que desde o início, a Igreja Renascer em

\footnotetext{
${ }^{26}$ O "mover de Deus" é a concepção que os organizadores divulgam no site oficial do evento. 
Cristo $^{27}$ conferiu-lhe um forte caráter musical, e já a partir da terceira edição, em 1995, os trios elétricos acompanhavam o deslocamento da multidão ao som de axé, baião, frevo, sertanejo etc, além de grupos de rap, hip-hop, rock e heavy metal.

As três edições que estudamos da "Marcha para Jesus" em Recife ocorreram, respectivamente, nos dias 14 de junho de 2008, 24 de outubro de 2009 e 25 de setembro de 2010. De acordo com a organização do evento e estimativas divulgadas pela mídia ${ }^{28}$, as três edições reuniram fiéis e participantes na ordem de 100 a 300 mil pessoas (2008 - 100 mil; 2009 - 150 mil e 2010 - 300 mil). Em todas as edições analisadas, o local da marcha foi a Zona Sul da cidade, na Avenida Boa Viagem, orla da praia urbana mais famosa de Recife, com seu trajeto a partir do $3^{\circ}$ Jardim até o Pólo Pina (local onde sempre é realizado um grande show com músicas gospel e com participação das Bandas Resgate, Renascer Praise - ambas ligadas a Igreja Renascer e muitas outras atrações evangélicas), situado no bairro vizinho do Pina. Nas três edições o horário estabelecido para a concentração da marcha foi às $12 \mathrm{~h}$ e a saída às $14 \mathrm{~h}$.

Entre os objetivos de manifestar publicamente a fé em Jesus Cristo, a Marcha para Jesus exalta os princípios cristãos e leva a cabo o propósito de evangelização de forma coletiva e efusiva. Neste afã, cada evento se torna uma ocasião especial para se colocar na posição de visitante e, num ato de reciprocidade e de manutenção da fé professada, exaltar bênçãos para a cidade anfitriã. Nos participantes das Marchas em Recife, o evento evidenciou uma postura de pertencimento, não só a uma igreja em particular, mas a uma comunidade de dimensões internacionais. Singularidades locais, códigos culturais e referenciais identitários, demarcaram tais lugares de pertencimento (com vestimentas típicas da cidade) mas assumiram, no contexto da globalização, o estatuto de narrativas que dialogam com outras representações e imagens acerca das identidades confessionais (roupas de "crente"). Somou-se a isso o fato de que as igrejas recifenses, mesmo demarcando seus lugares por meio dos trios patrocinados e identificados por faixas, se tornam unidas em um ato "público e conjunto" de fé - mesmo com

\footnotetext{
${ }^{27}$ A Igreja Apostólica Renascer em Cristo foi fundada em São Paulo, em 1986, por Estevam Hernandes e Sônia Hernandes. Inicialmente, as reuniões eram feitas no apartamento do casal, sendo posteriormente alugado um salão, num piso superior do edifício onde se encontrava a Pizzaria Livorno, na rua Vergueiro, no bairro de Vila Mariana, em São Paulo. Com o aumento do número de membros, foi disponibilizado um espaço, na Igreja Evangélica Árabe de São Paulo, ainda na Vila Mariana. O foco principal era em cultos para jovens, daí a forte ênfase musical da igreja e a sua estreita ligação com a realização das marchas no Brasil. Logo que começou foi uma das igrejas que mais investiu em mídias, comprando emissoras de rádio e TV.

${ }^{28}$ A Marcha, em todas as três edições analisadas foi transmitida ao vivo pela TV Nova (canal 22 UHF) e pela Rede Estação (canal 14 UFH), além da Rádio Maranata FM (103.9 MHz). Além dessas mídias, outros veículos noticiosos de Recife que deram destaque ao evento: Portais PE 360 graus e Pernambuco.com, jornais Folha de Pernambuco, Diário de Pernambuco e Jornal do Commercio e as emissoras TV Jornal e TV Globo.
} 
todas as suas muitas diferenças doutrinárias nos usos e costumes religiosos existentes entre elas.

Nas três edições que analisamos a ação performática coletiva não apresentou diferenças significativas entre os anos 2008, 2009 e 2010. Em todas as citadas edições, pessoas sem nenhuma ligação com a religião também participaram e os meios de comunicação de massa foram responsáveis por tal recrutamento, pois anunciaram amplamente os eventos dias antes das suas realizações, inclusive, na versão de 2010, esteve presente uma grande quantidade de pessoas de orientação homossexual. Por conta dessa peculiar presença, a mídia "promoveu" uma ligação com o fato de que a Parada da Diversidade teve sua realização, no mesmo local, duas semanas antes (12/09) - o que incomodou muitos participantes evangélicos, mas também fez com que outros, que deram entrevistas para a tevê, enxergassem uma boa oportunidade de evangelizar e "converter" tal grupo.

Pensar em mega-eventos como este é entender que eles fazem a mediação entre uma experiência pessoal e local e outra de dimensões globais. Para Siepierski (2001), mobilizações como essas são dispositivos que produzem efeitos tais como o sentido de pertencimento e a ilusão da unidade. E completa: "ao produzi-los, justifica-os. A Marcha é uma grande festa das aparências, certamente não despida de eficácia, pois nesses eventos uma comunidade imaginária pode ter existência".

A Marcha para Jesus em Recife pareceu apagar momentaneamente, as discriminações sociais, fazendo com que todos parecessem iguais, inclusive os homossexuais que se uniram à caminhada em 2010. O império da imagem midiática, tão amplamente noticiado nos jornais locais, transformou, em membros de um grupo, uma multidão de figurantes - fascinados pelo drama no qual são ao mesmo tempo atores e espectadores - o que estimulou o grupo a se mostrar "idealmente" e de modo espetacular. O espetáculo religioso das marchas em Recife, que ocupou o tão "dilatado" espaço midiático, é uma demonstração da nova forma de se viver a religiosidade contemporânea, e essa espetacularização remodelou os atores sociais participantes, engajando-os em um "outro espetáculo", no qual representaram não o que de fato são, mas o que devem ser em função do que eles imaginam que se espera deles.

O que se justifica exatamente porque, como lembra Mendes (2008, p.2), uma das balizas do protestantismo brasileiro é, geralmente, a sua proposta de diferenciar-se do catolicismo romano, o que evidencia, na visão do autor, que a Marcha para Jesus não aspira qualquer identificação com as 
procissões e as romarias promovidas pela Igreja Católica Apostólica Romana ${ }^{29}$. Apesar de que, cada vez mais, encontramos semelhanças entre mega-eventos evangélicos e católicos. Em ambos os casos, como ressalta Gomes (2008, p.56), aflora o proselitismo e a identificação/exposição imediata da "fé em ação" 30 .

\section{Considerações finais.}

Considerando as colocações acima descritas, observa-se que a relevância dos meios de comunicação na vida religiosa dos fiéis pressupõe, dialeticamente, tanto a presença de aspectos de uma recepção passiva e reprodutora, quanto momentos de subversão/transgressão, com possibilidades de resistência frente às demais confissões religiosas. Processo no qual ocorre não só a formação de consumidores em certa medida "passivos" e subordinados à lógica da Sociedade de Consumo, como também, possibilita novas formas de práticas religiosas e, portanto, ressignificadas.

Paradoxalmente a religião, vista como algo que transcende a materialidade, se transforma em mercadoria e passa a ser produzida em consonância com as leis do mercado e com vistas ao consumo de bens simbólicos. Por toda parte as mídias ressaltam ainda mais as suas cores e, no tempo presente, a religião parece aumentar a sua presença imagética em todas as partes do planeta, ajudando a instaurar um quadro social de profundas transformações. Dessa forma, as diversas instituições religiosas intensificam seu interesse pelo universo comunicacional e buscam dinamizar sua prática, ora como questionadora das funções sociais da comunicação, ora como usuária dos meios para a propagação de seus princípios e valores.

Neste espaço midiático, hoje tão disputado pelas instituições religiosas contemporâneas, surgem movimentos dinâmicos de aceitação/rejeição do "outro" concomitante com a emergência de um movimento generalizado de afirmação identitária, fundado no exclusivismo religioso. Nos casos observados, tanto o catolicismo que promove os showmissas, quanto o movimento evangélico reunido na Marcha para Jesus, apresentam uma espécie de transposição no plano organizativo institucional. Tal abordagem possibilita enxergarmos toda essa nova religiosidade midiática, espetacular e de ancoragem mercadológica, como determinante para a construção da identidade pessoal dos novos fiéis, sejam eles católicos conservadores, evangélicos tradicionais ou simpatizantes sincréticos de

\footnotetext{
${ }^{29}$ Tanto é que, no dia seguinte a Marcha de 2010, ocorreu na mesma Avenida Boa Viagem a $4^{\mathrm{a}}$ Caminhada Arquidiocesana "Sim à Vida", nos mesmos moldes da Marcha para Jesus: grande caminhada conduzida por trios elétricos, entretanto, com a propagação da mensagem católica.

${ }^{30}$ Que, segundo a autora, são características significativas do campo religioso atual, marcado por crescimento, visibilidade e diversificação de igrejas evangélicas, em especial, as pentecostais (GOMES, 2008, p.56).
} 
ambas as vertentes, percebendo que o que emerge nos mega-eventos religiosos são novas singularidades identitárias, que não somente mantém relações íntimas com a identidade coletiva católica ou protestante de outrora (que experimenta uma contínua elaboração da identidade coletiva, na medida que resgata a memória do passado, dá um sentido ao presente e aponta para o futuro (HERVIEU-LÉGER, 2005, p.70)), mas que também pode ser construída ou reformulada a partir da religiosidade midiática espetacular que se apresenta hoje $\mathrm{e}^{31}$.

Nesse sentido, o espetáculo observado nos showmissas e nas Marchas para Jesus, ou seja, a valorização das imagens religiosas (como representação visual e mental) vinculadas às mercadorias, por meio das quais as relações do consumo religioso são mediadas, está presente na vida cotidiana dos fiéis e diz respeito ao que os meios de comunicação produzem: por meio do cinema, da propaganda, da notícia, dos eventos e de programas televisivos, tais como noticiários, telenovelas e programas de auditório, entre outros, cria-se uma experiência que antecede a vivência real. "Toda a vida das sociedades nas quais reinam as modernas condições de produção se apresenta como uma imensa acumulação de espetáculos. Tudo o que era vivido diretamente tornou-se uma representação" (DEBORD, 1997, p. 13).

Essa conjuntura possibilitou e legitimou que a religião midiática ampliasse seu espaço na sociedade contemporânea, voltando a conquistar prestígio e a influenciar as comunidades religiosas já existentes - ainda que isso implique na transmutação delas mesmas, para que se pareçam cada vez mais com o espetacular mundo da mídia.

Portanto, na certeza de que a confluência entre religião e mídia contribui para novos tipos de comportamentos, colocamos aqui a necessidade de estudos mais aprofundados, que investiguem a natureza dessas inter-relações, posto que estas possibilitam o surgimento de novos produtos culturais no campo religioso e midiático.

\section{Referências}

ADORNO, Theodor W. A Indústria Cultural. In: Gabriel Cohn (org). Adorno. São Paulo: Ática, 1986 (Col. Os Grandes Cientistas Sociais No.54).

\footnotetext{
${ }^{31}$ Simmel sustentou que a religiosidade pode dar forma própria a relações sociais originalmente não religiosas, mostrando a conexão que existe entre as transformações sociais e o "a priori" religioso (que assume as vivências originadas no decorrer das relações sociais). : "tanto a coesão como a transformação social são formas de relações que supõem o mesmo conteúdo prático de vida. Além disso, ele sublinha que, quando as exigências sociais atingiram um grau suficiente de estabilidade e de harmonia emotiva, então elas são colocadas sob a égide da religião, e são, por assim dizer, "consagradas"” (MARTELLI, 2005, p. 247). Assim, a espetacularização, tendo sido reconhecida como relevante na vida social, adquire uma aura sagrada, ou seja, é transposta da esfera cultural original para a esfera religiosa (MENDES, 2008, p.111).
} 
ASSMANN, Hugo. A igreja eletrônica e seu impacto na América Latina: convite a um estudo. Petrópolis: Vozes, 1986.

BAUMAN, Zygmunt. Vida para consumo: a transformação de pessoas em mercadoria._Rio de Janeiro: Jorge Zahar Ed., 2008.

CAMPOS, L. S. Protestantismo brasileiro e mudança social. in: SOUZA, B. M. et al. (org.) Sociologia da religião e mudança social. São Paulo: Paulus, 2004. p. 106-136.

CANCLINI, Néstor Garcia. Consumidores e cidadãos. Conflitos culturais da globalização Rio de Janeiro: UFRJ, 1997.

CARRANZA, Brenda. Renovação Carismática Católica: origens, mudanças e tendências. Aparecida: Santuário, 2000.

CUNHA, Magali do Nascimento. A explosão gospel: um olhar das ciências humanas sobre o cenário evangélico no Brasil. Rio de Janeiro: Mauad X; Instituto Mysterium, 2007.

DEBORD, Guy. A sociedade do espetáculo. Rio de Janeiro: Contraponto, 1997.

DOLGHIE, Jacqueline Ziroldo e CAMPOS, Breno Martins. Sacerdócio, mercadoria e espetáculo. Uma perspectiva teórica do consumo de música evangélica no Brasil. Revista Pandora Brasil No 25 - Dezembro de 2010.

DOWNING, John D.H. Mídia Radical, Rebeldia nas comunicações e movimentos sociais. Senac, São Paulo, 2002

FEATHerstone, M. Cultura de Consumo e Pós-Modernismo. São Paulo: Studio Nobel, 1995.

FRESTON, P. Protestantismo e política no Brasil. Tese de doutorado em Ciências Sociais. Campinas: UNICAMP, 1993.

GOMES, Edlaine de Campos. Onde está o pluralismo: manifestações da religião na metrópole. In: ENFOQUES on-line: Revista Eletrônica dos alunos do Programa de PósGraduação em Sociologia/Universidade Federal do Rio de Janeiro, Instituto de Filosofia e Ciências Sociais, Programa de Pós-Graduação em Sociologia e Antropologia. - V.7, n.1 (Março, 2008). - Rio de Janeiro: PPGSA, 2008.

GONÇALVES, Antônio. Comunicação e Religião. São Paulo: Ultimato, 2002.

HALL, S. A identidade cultural na pós-modernidade. Rio de Janeiro. Ed. DP\&A. 2001.

HERVIEU-LÉGER, Danièle. La religion en mouvement, le pélerin et le converti. Flamarion, 1999.

KLEIN, Alberto. Imagens de culto e imagens da mídia. Interferências midiáticas no cenário religioso. Porto Alegre: Sulina, 2006. 
MARIANO, Ricardo. Neopentecostalismo: os pentecostais estão mudando. São Paulo: dissertação de mestrado em sociologia, FFLCH-USP, 1995.

MARTELLI, Stefano. A religião na sociedade pós-moderna: entre secularização e desseculrização. São Paulo: Paulinas, 1995.

MENDES, Napoleão Marcos de Moura. Ritual, communitas $\boldsymbol{e}$ espetáculo religioso na Marcha Para Jesus em Fortaleza-CE. Revista de Ciências Sociais volume 39 nº 2, 2008.

MENDONÇA, A. G. Um panorama do protestantismo brasileiro atual In Leilah Landim (org.) Sinais dos tempos: tradições religiosas no Brasil. RJ: ISER, 1989. p.37-86.

ORO, Ari Pedro. Igreja Universal do Reino de Deus: os novos conquistadores da fé. São Paulo: Paulus, 2003.

ORO, Ari Pedro. Religiões Pentecostais e meios de comunicação de massa no Sul do Brasil.

PIERUCCI, A \& PRANDI, R. A realidade social das religiões no Brasil. São Paulo: HUCITEC, 1996.

PIERUCCI, Antonio Flávio. Cadê a nossa diversidade religiosa? In: As Religiões no Brasil: Continuidades e Rupturas. TEIXEIRA, Fautino e MENEZES, Renata (orgs). Petrópolis, RJ: Vozes, 2006.

Revista eclesiástica brasileira, 50, 198, junho, p. 304-334.

REVISTA VEJA Edição 2098, 4 de fevereiro de 2009.

SIEPIERSKI, Carlos Tadeu. De bem com a vida: O sagrado num mundo em transformação. Um estudo sobre a Igreja Renascer em Cristo e a presença evangélica na sociedade brasileira contemporânea. Tese apresentada ao Departamento de Antropologia Social da Faculdade de Filosofia, Letras e Ciências Humanas da Universidade de São Paulo USP, 2001.

SIMMEL, Georg. Essays on Religion. Yale: Yale University Press - Durham, 1997.

SOUZA, André Ricardo de. Igreja in concert: padres cantores, mídia e marketing. São Paulo: Annablume: Fapesp, 2005.

THOMPSON, J.B. Mídia e modernidade. Uma teoria social da mídia. Rio de Janeiro: Vozes, 2002.

VATTIMO, G. A sociedade transparente. Lisboa: Relógio D`Água, 1992.

O Fim da Modernidade. São Paulo: Martins Fontes, 1996.

WOLTON, Dominique. É preciso salvar a comunicação. São Paulo: Paulus, 2006. 


\section{Bibliografia}

ADORNO, T.W.; HORKHEIMER, M. Dialética do esclarecimento: fragmentos filosóficos. Trad. Guido Antonio de Almeida. 2.ed. Rio de Janeiro, Jorge Zahar, 1986.

BAUDRILlAR, Jean. A Sociedade de Consumo. Lisboa; Edições 70, 1995.

CAMPOS, Leonildo Silveira. Teatro, Templo e Mercado: Organização e Marketing de um empreendimento neopentecostal. Petrópolis, RJ: Vozes; São Paulo, Simpósio Editora e Universidade Metodista de São Paulo, 1997.

FONSECA, Alexandre Brasil. Evangélicos e mídia no Brasil. Dissertação de Mestrado. RJ: PPGSA. IFCS/UFRJ, 1997.

FRESTON, Paul. Protestantes e política no Brasil: da Constituinte ao impeachment. Tese de Doutorado, Campinas, IFCH-Unicamp, 1993.

MENDONÇA, Antonio Gouveia. Protestantismo brasileiro, uma breve interpretação histórica. In: Sociologia da Religião e mudança Social: Católicos, protestantes e novos movimentos religiosos no Brasil. SOUZA, Beatriz Muniz de e MARTINO, Luiz Mauro Sá, (orgs.) São Paulo: Paulus, 2004.

PIERUCCI, Antônio Flávio \& PRANDI, Reginaldo. A realidade social das religiões no Brasil. São Paulo, Hucitec, 1996.

PUNTEL, Joana T. A Igreja e a democratização da comunicação. S. Paulo: Paulinas, 1994.

Original submetido em; 11/06/2013

Aprovado para publicação em 22/10/2014

Sobre os autores

Karla Patriota Bronsztein

Doutora em Sociologia e mestre em Comunicação pela UFPE. Professora no Departamento de Comunicação e do Programa de Pósgraduação em Comunicação da Universidade Federal de Pernambuco - UFPE.

Maria Lúcia Bastos Alves Doutora em Sociologia pela Universidade de São Paulo, mestre em

Ciências Sociais pela Universidade Federal do Rio Grande do Norte. Professora Associada II da Universidade Federal do Rio Grande do Norte.- UFRN 